\title{
A safe, simple, and facile staining method using polysiloxanes for high-contrast visualization of gelator aggregates by transmission electron microscopy
}

\author{
Kenji Hanabusa, ${ }^{* 1,} 2$ Masashi Nakashima, ${ }^{3}$ Eriko Funatsu, ${ }^{3}$ Sachiyo Kishi, ${ }^{3}$ and Masahiro Suzuki ${ }^{1}$ \\ ${ }^{1}$ Interdisciplinary Graduate School of Science and Technology, Shinshu University, Ueda, 386-8567 \\ 2 Division of Frontier Fibers, Institute for Fiber Engineering, ICCER, Shinshu University, Ueda, 386-8567 \\ ${ }^{3}$ Faculty of Textile Science \& Technology, Shinshu University, Ueda, 386-8567 \\ E-mail: hanaken@shinshu-u.ac.jp
}

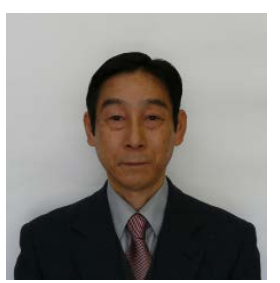

Kenji Hanabusa

In 1979, Kenji Hanabusa started his academic carrier at Shinshu University as an Assistant Professor. He received Ph.D. from Osaka University in 1981 in Japan. In 1987, he was promoted to an Associate Professor, and since 1999, he has been a Full Professor in the Interdisciplinary Graduate School of Science and Technology at Shinshu University. His research interest is the development of low-molecular weight gelators and thickeners on the basis of supramolecular chemistry.

\begin{abstract}
The staining of TEM samples using Si atoms was investigated using aggregates of loose gels formed by twelve structurally different gelators in several solvents. Thirteen commercially available siloxanes were used as stains. TEM images of nonstained and $\mathrm{OsO}_{4}$-stained samples of molecular aggregates formed by the dodecamethylenediamide of $\mathrm{N}$ methacryloyloxyethylaminocarbonyl-L-isoleucine in 1propanol were poorly defined and low-contrast. However, the image of a methacryloyloxypropyl-terminated polydimethylsiloxane (S1)-stained sample was characterized by very clear bundles of fine fibers. The staining effect was explained by the wrapping of fibers, the stabilizing of the individual fibers, and reinforcing by $\mathbf{S 1}$. An $\mathbf{S 1}$ concentration of more than $5 \mathrm{mg} \mathrm{mL}^{-1}$ was found to be necessary for satisfactory contrast. S1 was successfully applied to the observation of aggregates of eleven other gelators. S1 worked universally as an aggregate stain regardless of the gelator or solvent polarity. The staining effect was observed for other siloxanes. This effect was found to depend on the molecular weight of the siloxane (> 1,000) rather than the kind of siloxane employed. Energydispersive X-ray spectroscopy indicated that the molecules of $\mathbf{S 1}$ gather on the surface of the fibers during drying, wrapping them. The results indicate that the present staining method guarantees reproducibility and universality.
\end{abstract}

\section{Introduction}

Transmission electron microscopy (TEM) is a technique in which a beam of electrons is transmitted through a sample to form an image. The sample investigated is typically an ultrathin section or a suspension mounted on a grid. An image results from the interaction between the electrons and the sample as the beam is transmitted through the sample. The image is magnified and focused onto an imaging device, such as a fluorescent screen or a sensor such as a charge-coupled device (CCD). Historically, TEM was first demonstrated by Max Knoll and Ernst Ruska in 1931, and the first TEM with higher resolution than optical microscopes was built by Rusk in 1933, with the first commercial version being completed in 1939. In 1986, Ruska was awarded the Nobel Prize in physics for the development of TEM.

TEM can provide images at significantly higher resolutions than those available using optical microscopy because the wavelength of electrons is smaller than those of light. As a result, TEM is a major analytical method in biology, physics, and chemistry. As demonstrated by the breadth of literature on TEM, it has made significant contributions to science, particularly the biological sciences. ${ }^{1-6}$ However, the contribution of TEM to chemistry has also rapidly increased in recent years. The earliest examples of TEM usage in chemistry are a series of pioneering studies by Kunitake's group on synthetic bilayer membranes in which TEM was used to obtain images of the structures of artificial amphiphiles negatively stained with uranyl acetate. ${ }^{7-10}$

TEM is now widely and routinely used in polymer science. For example, the morphology of block copolymers, ${ }^{11-19}$ blend polymers, ${ }^{20-22}$ dendrimers, ${ }^{23-25}$ spun core/shell fibers, ${ }^{26}$ copolymer latex particles, ${ }^{27}$ graft-copolymers on natural rubber, ${ }^{28}$ and composite particles of epoxy-polymers ${ }^{29}$ have been studied using TEM.

In general, TEM samples need high-atomic-number stains for enhanced contrast. This staining material absorbs or scatters part of the electron beam. Heavy-metal-containing compounds are used prior to TEM observation to selectively deposit electron-dense atoms on the sample. Uranyl acetate, ${ }^{7-10,23,24}$ osmium tetroxide $\left(\mathrm{OsO}_{4}\right){ }^{11,16,19,20,22,26,28}$ ruthenium tetroxide $\left(\mathrm{RuO}_{4}\right),{ }^{13-15,17,18,21,27}$, and phosphotungstic acid $\left(\mathrm{H}_{3} \mathrm{PW}_{12} \mathrm{O}_{4}\right)^{29-34}$ are widely employed as stains. Even though uranyl acetate is a radioactive compound and both $\mathrm{OsO}_{4}$ and $\mathrm{RuO}_{4}$ are extremely toxic oxidizing agents that must be handled with utmost care, surprisingly little research effort has been dedicated to developing non-hazardous stains for TEM. As a rare example, Stara et al. reported oleum, a $\mathrm{H}_{2} \mathrm{SO}_{4}$ solution of $\mathrm{SO}_{3}$, as a new and simple staining method. ${ }^{35}$ However, oleum is a strongly toxic oxidizing solution. Furthermore, Mann et al. reported two potentially useful stains, i.e., the commercially available $\mathrm{Gd}(\mathrm{fod}) 3$, where fod is 1,1,1,2,2,3,3-heptafluoro-7,7-dimethyl4,6-octadione, and a molybdenum complex prepared from tbutylammonium molybdate and docosylphosphonic acid. ${ }^{36}$ 
In recent years, considerable research effort has been dedicated to the development of low-molecular-weight gelators that physically gel water or organic solvents. Accordingly, with advances in supramolecular chemistry, an increasing number studies on gelators have been published in recent years. ${ }^{37-57}$ Low-molecular-weight gelators exhibit a unique characteristic in that they immobilize substantial volumes of solvent at low concentration. Gelators are also characterized by thermally reversible sol-gel transitions. These features can be attributed to the formation of three-dimensional (3D) network structures mediated by noncovalent interactions such as hydrogen bonding, electrostatic interactions, van der Waals interactions, and $\pi-\pi$ interactions. The visual imaging of 3D network structures is very important in the investigation of gelation mechanisms. Accordingly, electron microscopic observation is routinely used to obtain information on the network structures of aggregates formed by gelators. To the best of our knowledge, the first study of gels using scanning electron microscopy (SEM) was reported by Tachibana et al. in 1969, ${ }^{58}$ who obtained SEM images of the left- and right-handed twists of the D- and L-forms of 12hydroxystearic acid in an ethanol gel. The observation of aggregates in gels using TEM was first reported in 1987 by Terech et al, ${ }^{59}$ who published both TEM and SEM images of a native steroid in a cyclohexane gel. Over the last two decades, our group has developed several low-molecular-weight gelators and succeeded in imaging their 3D network structures by SEM and TEM. ${ }^{60-65}$

We herein report a novel, simple, and safe staining method for visualizing molecular aggregates of gelators in TEM using polysiloxanes as stains, which are commercially available, inexpensive, non-toxic, and provide high-contrast images. This is the first attempt to use polysiloxanes as stains for TEM.

\subsection{Instrumentation}

\section{Experimental}

Elemental analysis was performed with a Perkin-Elmer 240B analyzer. Infrared spectra were recorded on a Jasco FTIR-7300 spectrometer using $\mathrm{KBr}$ plates. ${ }^{1} \mathrm{H}$ NMR spectra were obtained on a Bruker AVANCE 400 spectrometer. TEM was performed with a JOEL IEM-2010 electron microscope. Energy dispersive $\mathrm{X}$-ray spectrometry (EDS) was performed using a NORAN Voyager 1000 attached to a JOEL TEM-2010.

\subsection{Reagents}

9-Decenol, triphosgene, and 2-chloro-4,6-dimethoxy-1,3,5triazine (CDMT) were purchased from Tokyo Chemical Industry Co., Ltd. Poly(ethylene glycol) (average $\mathrm{Mn}=10,000$ ), Karstedt's catalyst solution, 1,1,1,3,5,5,5-heptamethylsiloxane, and 2-chloro-1,3,2-dioxaphospholane 2-oxide were supplied by Aldrich. The siloxanes methacryloyloxypropyl-terminated polydimethylsiloxane (S1), 1,3-bis(3-methacryloyloxypropyl) tetramethylsiloxane (S2), aminopropyl-terminated polydimethylsiloxane (S3 and S4), carbinol-terminated polydimethylsiloxane (S5), octamethylcyclotetrasiloxane (S12), and decamethylcyclopentasiloxane (S13) were obtained from Gelest Inc. KF-96-10cs (S6), KF-96-50cs (S7), KF-96-100cs (S8), KF96-300cs (S9), KF-50-100cs (S10), and KF-54 (S11) were purchased from Nacalai Tesque Inc. Osmium tetroxide $\left(\mathrm{OsO}_{4}\right)$ was purchased from Wako Pure Chemicals.

\subsection{Gelation test}

Gelation tests were performed using the inverted test-tube method. A typical procedure was as follows: A weighed sample and $1 \mathrm{~mL}$ of solvent in a septum-capped test-tube with an internal diameter of $14 \mathrm{~mm}$ was heated until the solid dissolved. The resulting solution was allowed to cool and held at $25^{\circ} \mathrm{C}$ for $2 \mathrm{~h}$ and the gelation was then checked visually. When no fluid ran down the wall upon inversion of the test-tube it was judged to be a gel. Gelation ability was evaluated in terms of the minimum gel concentration, which is defined as the concentration in $\mathrm{g} \mathrm{L}^{-1}$ (gelator/solvent) necessary for gelation at $25{ }^{\circ} \mathrm{C}$.

\subsection{Synthesis}

Dodecamethylenediamide of $N$-methacryloyloxyethylaminocarbonyl-L-isoleucine (G1): To a solution of $42.98 \mathrm{~g}$ (0.162 mol) of $N$-benzyloxycarbonyl-L-isoleucine in $150 \mathrm{~mL}$ of ethyl acetate was added $36.73 \mathrm{~g}(0.178 \mathrm{~mol})$ of $N, N^{\prime}$ dicyclohexylcarbodiimide at $0{ }^{\circ} \mathrm{C}$. After the mixture was stirred for $1 \mathrm{~h}$ at $0{ }^{\circ} \mathrm{C}$, a solution of $16.22 \mathrm{~g}(0.081 \mathrm{~mol})$ of 1,12 dodecamethylenediamine in $150 \mathrm{~mL}$ of chloroform was added, and this solution was stirred for $2 \mathrm{~h}$ at $0{ }^{\circ} \mathrm{C}$ for a further $2 \mathrm{~h}$ at room temperature. The resulting mixture was stirred for $10 \mathrm{~h}$ at $40{ }^{\circ} \mathrm{C}$ and then at $55^{\circ} \mathrm{C}$ overnight. After removing the formed dicyclohexylurea by hot filtration, the filtrate was cooled to room temperature and the gel formed was suction filtered and dried. The crude product was dissolved in $1.2 \mathrm{~L}$ of hot 1 propanol and cooled to room temperature. The gel formed was broken well using a mechanical stirrer and suction filtered. After repeating this purification with 1-propanol, $45.48 \mathrm{~g}(81 \%)$ of the dodecamethylenediamide of $N$-benzyloxycarbonyl-L-isoleucine was obtained.

The dodecamethylenediamide of $N$-benzyloxycarbonyl-Lisoleucine $(45.48 \mathrm{~g}, 0.065 \mathrm{~mol})$ was hydrogenated in the presence of Pd-C in $500 \mathrm{~mL}$ of 1-propanol for $5 \mathrm{~h}$ at room temperature under a hydrogen atmosphere. After confirming the complete removal of the protecting group by silica gel TLC (chloroform/methanol/acetic acid, 95:5:1, $v / v / v$ ) using ninhydrin visualization, the solution was filtered. The filtrate was evaporated and recrystallization from a mixture of $100 \mathrm{~mL}$ THF and $200 \mathrm{~mL}$ of petroleum ether provided $19.69 \mathrm{~g}(70 \%)$ of the dodecamethylenediamide of L-isoleucine.

To a hot solution of $1.06 \mathrm{~g}$ ( $3.39 \mathrm{mmol})$ of the dodecamethylenediamide of L-isoleucine in $80 \mathrm{~mL}$ of toluene was added $1.44 \mathrm{~g}$ ( $6.78 \mathrm{mmol})$ of 2-methacryloyloxyethylisocyanate dropwise. After stirring for $30 \mathrm{~min}$ at $80{ }^{\circ} \mathrm{C}$, the product was precipitated by adding $100 \mathrm{~mL}$ of hexane. Recrystallization from $50 \mathrm{~mL}$ of 2-methoxyethanol gave $2.20 \mathrm{~g}$ (88\%) of G1. FT-IR $\left(\mathrm{KBr}, \mathrm{cm}^{-1}\right): 3282(\mathrm{vN}-\mathrm{H}$ amide $), 2849\left(\mathrm{vCH}_{2}\right), 1722(\mathrm{vC}=\mathrm{O}$ ester), 1631 ( $v \mathrm{C}=\mathrm{O}$, amide I), 1568 ( $\delta \mathrm{N}-\mathrm{H}$ amide II). Found: $\mathrm{C}$ 61.51, H 8.97, N 11.51\%. Calcd for $\mathrm{C}_{38} \mathrm{H}_{68} \mathrm{~N}_{6} \mathrm{O}_{8}$ : C 61.93, H 9.30, N 11.40\%. ${ }^{1} \mathrm{H}-\mathrm{NMR}\left(400 \mathrm{MHz}\right.$, DMSO-d 6 , TMS, $\left.25{ }^{\circ} \mathrm{C}\right): \delta=$ 0.78-0.82 (d, 12H; $\mathrm{CH}_{3}$-isoleucyl), 1.22 (br, $24 \mathrm{H}$; alkyl), 1.39 (m, $4 \mathrm{H}$; $\mathrm{CONHCH}_{2} \underline{\mathrm{CH}_{2}}$ ), 1.56 (m, 2H; $-\underline{\mathrm{CH}}$-isoleucyl), 1.88 (s, $6 \mathrm{H}$; $\left.\mathrm{COC}\left(\underline{\mathrm{CH}_{3}}\right)=\mathrm{CH}_{2}\right), 3.02\left(\mathrm{~m}, 4 \mathrm{H} ; \underline{\mathrm{CH}_{2}} \mathrm{NHCO}\right), 3.29(\mathrm{~m}, 4 \mathrm{H}$; NHCONHCH 2 ), 3.98 (d, 2H; $\mathrm{NH} \underline{\mathrm{CHCO}}$ ), 4.06 (t, 4H; $\left.\mathrm{NHCH}_{2} \underline{\mathrm{CH}_{2} \mathrm{O}}\right), 5.68,6.06\left(\mathrm{~s}, 1 \mathrm{H} ; \mathrm{COC}\left(\mathrm{CH}_{3}\right)=\underline{\mathrm{CH}_{2}}\right), 6.10(\mathrm{~d}, 2 \mathrm{H}$; $\underline{N H C O N H}), \quad 6.22$ (t, 2H; $\left.\mathrm{NHCONHCH}_{2}\right), 7.92$ (t, 2H; $\mathrm{CH}_{2}$ NHCO).

1,1,1,3,5,5,5-heptamethylsilyldecyloxycarbonyl-L-isoleucylaminooctadecane (G3): Pyridine ( $2.64 \mathrm{~g}, 33.3 \mathrm{mmol}$ ) and 15.63 $\mathrm{g}(100 \mathrm{mmol})$ of 9-decenol were added to a solution of $9.89 \mathrm{~g}$ (33.3 mmol) of triphosgene in $50 \mathrm{~mL}$ of dichloromethane cooled in an in ice-water bath in 5 portions over a period of $1 \mathrm{~h}$. The solution was stirred at room temperature for 3 days and then 100 $\mathrm{mL}$ of hexane was added. The precipitated pyridinium chloride was filtered off and the resulting solution was evaporated. Vacuum distillation using a glass tube oven gave $17.86 \mathrm{~g}(82 \%)$ of 9-decenoxycarbonyl chloride $\left(1779 \mathrm{~cm}^{-1}\right.$ for $v \mathrm{C}=\mathrm{O}$ in chloroformate).

L-Isoleucylaminooctadecane ${ }^{66}$ (13.87 $\left.\mathrm{g}, 36.3 \mathrm{mmol}\right)$ and $4.41 \mathrm{~g}$ (43.6 mmol) of triethylamine were dissolved in $80 \mathrm{~mL}$ of THF and then $7.93 \mathrm{~g}$ (36.3 mmol) of 9-decenoxycarbonyl chloride was added at $0{ }^{\circ} \mathrm{C}$. After stirring for $1 \mathrm{~h}$ at room temperature, the triethylammonium chloride was removed and the solvent evaporated. The residue was dissolved in $200 \mathrm{~mL}$ of 
hot methanol and cooled. The gel formed was broken well using a mechanical stirrer and suction filtered. Purification twice with methanol gave $14.75 \mathrm{~g}$ (72\%) of 9-decenoxycarbonyl-Lisoleucylaminooctadecane. FT-IR $\left(\mathrm{KBr}, \mathrm{cm}^{-1}\right): 3292(\mathrm{vN}-\mathrm{H}$ amide $), 2850\left(\mathrm{vCH}_{2}\right), 1691(\mathrm{vC}=\mathrm{O}$ urethane $), 1645(\mathrm{vC}=\mathrm{O}$, amide I), 910 ( $\delta \mathrm{C}-\mathrm{H}$ terminal olefin). Found: C 73.59, H 12.95, N 5.03\%. Calcd for $\mathrm{C}_{35} \mathrm{H}_{68} \mathrm{~N}_{2} \mathrm{O}_{3}$ : C 74.41, $\mathrm{H}$ 12.13, N 4.96\%. ${ }^{1} \mathrm{H}-\mathrm{NMR}\left(400 \mathrm{MHz}\right.$, DMSO-d 6 , TMS, $\left.25^{\circ} \mathrm{C}\right): \delta=5.85$ (d, $1 \mathrm{H}$; OCONH-), 5.80 (t, 1H, -CONH-), 5.22 (m, 1H, $\mathrm{CH}_{2}=\mathrm{C} \underline{\mathrm{H}}-$ ), 4.96 (d, 2H, $\left.\underline{\mathrm{C}}_{2}=\mathrm{CH}-\right), 4.04$ (t, 2H, -OCH $\left.2-\right), 3.09$ (t, 1H, COCHNH-), 2.05 (m, 1H, $\mathrm{CH}_{3} \mathrm{CH}_{2} \mathrm{CH}-$ ), 1.90 (q, 2H, $\mathrm{CH}_{2}=\mathrm{CH}-$ $\left.\mathrm{C}_{2}-\right)$, 1.60 (m, $\left.2 \mathrm{H},-\mathrm{OCH}_{2} \underline{\mathrm{C}}_{2}\right), 1.49$ (m, 2H, - $\mathrm{NHCH}_{2} \mathrm{C}_{2}-$ ), 1.26 (s, $\left.42 \mathrm{H},-\mathrm{CH}_{2}-\right), 0.92$ (q, $6 \mathrm{H}, \mathrm{CH}_{3}$ in isoleucyl), 0.88 (t, $3 \mathrm{H}$, $\mathrm{CH}_{3}$ in octadecyl).

Karstedt's catalyst solution $(60 \mu \mathrm{L})$ was added to a solution of $4.00 \mathrm{~g}$ (7.08 mmol) of 9-decenoxycarbonyl-L-isoleucylaminooctadecane in $150 \mathrm{~mL}$ of dry toluene and then $2.05 \mathrm{~g}(9.20$ mmol) of 1,1,1,3,5,5,5-heptamethylsiloxane was added slowly followed by stirring for 2 days at $55{ }^{\circ} \mathrm{C}$ under an argon atmosphere. After confirming the disappearance of the terminal olefin by IR $\left(910 \mathrm{~cm}^{-1}\right)$, the solvent was removed and the resulting matter was dissolved in $150 \mathrm{~mL}$ of hot methanol followed by charcoal treatment. The filtrate without charcoal was left to stand at room temperature and the gel formed was broken well and filtered. Charcoal treatment twice of the methanol solution gave $3.93 \mathrm{~g}$ (72\%) of G3. FT-IR $\left(\mathrm{KBr}, \mathrm{cm}^{-1}\right)$ : $3294\left(v \mathrm{~N}-\mathrm{H}\right.$ amide), $2850\left(\mathrm{vCH}_{2}\right), 1691(\mathrm{vC}=\mathrm{O}$ urethane $), 1645$ $(v \mathrm{C}=\mathrm{O}$, amide I), $1050(v \mathrm{Si}-\mathrm{O}-\mathrm{Si})$, disappeared $910(\delta \mathrm{C}-\mathrm{H}$ terminal olefin). Found: C 63.47, H 12.05, N 3.71\%. Calcd for $\mathrm{C}_{42} \mathrm{H}_{90} \mathrm{~N}_{2} \mathrm{O}_{5} \mathrm{Si}_{3}: \mathrm{C}$ 64.06, H 11.52, N 3.56\%. ${ }^{1} \mathrm{H}-\mathrm{NMR}(400 \mathrm{MHz}$, DMSO-d, $\left.\mathrm{TMS}, 25^{\circ} \mathrm{C}\right): \delta=5.87(\mathrm{~d}, 1 \mathrm{H}$; $-\mathrm{OCONH}-), 5.19(\mathrm{t}$, $1 \mathrm{H}, \mathrm{CONH}-)$, 4.04 (t, 2H, -OCH2-), 3.89 (t, 1H, -COCㅌNH-), 3.25 (q, $\left.2 \mathrm{H},-\mathrm{NHCH}_{2}-\right) 1.87$ (m, $1 \mathrm{H},-\mathrm{C} \underline{\mathrm{H}}-$ isoleucyl), 1.66 (m, $\left.2 \mathrm{H},-\mathrm{OCH}_{2} \underline{\mathrm{C}}_{2}\right), 1.59$ (m, 2H, $\left.-\mathrm{SiCH}_{2} \underline{\mathrm{CH}}_{2}-\right), 1.48$ (m, 2H, $\left.\mathrm{NHCH}_{2} \underline{\mathrm{CH}}_{2}-\right), 1.25$ (s, $44 \mathrm{H},-\mathrm{CH}_{2}$ - and $\mathrm{CH}_{3} \underline{\mathrm{C}}_{2}$ - isoleucyl), 0.92 (q, $6 \mathrm{H}, \mathrm{CH}_{3}$ in isoleucyl), 0.88 (t, 3H, $\mathrm{CH}_{3}$ in octadecyl), 0.45 (t, $2 \mathrm{H},-\mathrm{SiCH}_{2}-$ ), 0.15 (s, 3H, -SiCH3), 0.083 (s, 18H, -Si-CH3).

1-Undecylcarbonylamino-3,5-bis(rac-sec-butylamino-

carbonyl)benzene (G6): A solution of $200 \mathrm{~mL}$ of pyridine containing $54.35 \mathrm{~g}(0.30 \mathrm{~mol})$ of 5-aminoisophthalic acid was cooled in an ice-water bath and then $69.37 \mathrm{~g}(0.30 \mathrm{~mol})$ of dodecanoyl chloride was added by portions over $1 \mathrm{~h}$. After stirring for $3 \mathrm{~h}$ at room temperature, evaporation of pyridine followed by recrystallization from $300 \mathrm{~mL}$ of methanol provided $85.60 \mathrm{~g}$ (79\%) of 5-undecylcarbonylaminoisophthalic acid. FTIR $\left(\mathrm{KBr}, \mathrm{cm}^{-1}\right): 3268(v \mathrm{~N}-\mathrm{H}$ amine $), 2921\left(\mathrm{vCH}_{3}\right), 2849\left(\mathrm{vCH}_{2}\right)$, $1722(\mathrm{vC}=\mathrm{O}$ carboxylic acid $), 1662(\mathrm{vC}=\mathrm{O}$, amide $\mathrm{I}), 1543(\delta \mathrm{N}-$ $\mathrm{H}$ amide II). Found: C 52.74, H 7.83, N 2.52\%. Calcd for $\mathrm{C}_{20} \mathrm{H}_{29} \mathrm{NO}_{5}$ : C 66.09, H 8.04, N 3.85\%. ${ }^{1} \mathrm{H}-\mathrm{NMR}(400 \mathrm{MHz}$, DMSO-d 6 , TMS, $25^{\circ} \mathrm{C}$ ): $\delta=13.19(\mathrm{~s}, 2 \mathrm{H}, \mathrm{COOH}), 10.22(\mathrm{~s}, 1 \mathrm{H}$, $\mathrm{NH}$ ), 8.43 (s, 2H, 2-benzene), 8.14 (s, 1H, 4-benzene), 2.33 (t, $\left.2 \mathrm{H}, \mathrm{NHCOC}_{2} \mathrm{CH}_{2}\right), 1.60$ (m, 2H, $\left.\mathrm{NHCOCH}_{2} \underline{\mathrm{C}}_{2}\right), 1.26$ (m, $\left.16 \mathrm{H}, \mathrm{CH}_{2} \mathrm{CH}_{3}\right), 0.84$ (t, 3H, $\left.\mathrm{CH}_{3}\right)$.

A solution of $3.63 \mathrm{~g}(0.010 \mathrm{~mol})$ of 5-undecylcarbonylaminoisophthalic acid and $3.51 \mathrm{~g}$ (0.020 mol) of CDMT in 100 $\mathrm{mL}$ of dry THF was cooled in a salt-and-ice-water bath, $2.5 \mathrm{~mL}$ ( $0.022 \mathrm{~mol})$ of 4-methylmorpholine was added dropwise at -5 to $0{ }^{\circ} \mathrm{C}$. After stirring for $3 \mathrm{~h}$ at 0 to $3{ }^{\circ} \mathrm{C}, 1.46 \mathrm{~g}(0.020 \mathrm{~mol})$ of racsec-butylamine was added dropwise at -5 to $0{ }^{\circ} \mathrm{C}$. The resulting mixture was stirred for $2 \mathrm{~h}$ at 0 to $3{ }^{\circ} \mathrm{C}$ and then overnight at room temperature. The residue after evaporation was dissolved in $100 \mathrm{~mL}$ ethyl acetate and washed successively with water, 1 $\mathrm{M} \mathrm{NaOH}$, water, $1 \mathrm{M} \mathrm{HCl}$, and water. After evaporation of ethyl acetate, recrystallization from a small amount of ethyl acetate gave $4.24 \mathrm{~g}$ (87\%) of G6. FT-IR ( $\left.\mathrm{KBr}, \mathrm{cm}^{-1}\right): 3295$ ( $v \mathrm{~N}-\mathrm{H}$ amine), $2924\left(v^{2} H_{3}\right), 2853\left(v \mathrm{CH}_{2}\right), 1636(v \mathrm{C}=\mathrm{O}$, amide I $), 1536(\delta \mathrm{N}-\mathrm{H}$ amide II). Found: C 71.01, H 10.02, N 9.14\%. Calcd for $\mathrm{C}_{29} \mathrm{H}_{47} \mathrm{~N}_{3} \mathrm{O}_{3}$ : C 71.00, H 10.00, N 8.87\%. ${ }^{1} \mathrm{H}-\mathrm{NMR}(400 \mathrm{MHz}$, $\mathrm{CDCl}_{3}$, TMS, $\left.25^{\circ} \mathrm{C}\right): \delta=8.62\left(\mathrm{~s}, 1 \mathrm{H}, \mathrm{NHCOCH}_{2} \mathrm{CH}_{2}\right), 8.27(\mathrm{~s}$, 2H, 2-benzene), 7.93 (s, 1H, 4-benzene), 6.31 (d,2H, $\left.\mathrm{CON} \underline{\mathrm{H} C H}\left(\mathrm{CH}_{3}\right) \mathrm{CH}_{2} \mathrm{CH}_{3}\right), \quad 4.10 \quad(\mathrm{~m}, \quad 2 \mathrm{H}$ (CONHCH$\left.\left(\mathrm{CH}_{3}\right) \mathrm{CH}_{2} \mathrm{CH}_{3}\right), 2.42$ (t, $\left.2 \mathrm{H}, \mathrm{NHCOC}_{2} \mathrm{CH}_{2}\right), 1.70$ (m, 2H, NHCOCH $\left.\mathrm{CH}_{2}\right), 1.57$ (m, 4H, $\left.\mathrm{CH}\left(\mathrm{CH}_{3}\right) \mathrm{CH}_{2} \mathrm{CH}_{3}\right), 1.31$ (d, $\left.6 \mathrm{H}, \mathrm{CH}\left(\mathrm{CH}_{3}\right) \mathrm{CH}_{2} \mathrm{CH}_{3}\right), 1.24\left(\mathrm{~m}, 16 \mathrm{H}, \mathrm{CH}_{2} \mathrm{CH}_{3}\right), 0.96$ (t, 3H, $\left.\mathrm{CH}_{2} \mathrm{CH}_{2} \mathrm{CH}_{3}\right)$.

\section{1-Undecylcarbonylamino-3,5-bis(1-ethylpropylamino-}

carbonyl)benzene (G7); This compound was prepared using 2ethylpropylamine by the same procedure as that used for G6. Yield; 70\%. FT-IR (KBr, $\left.\mathrm{cm}^{-1}\right): 3264$ ( $\mathrm{vN-H}$ amine), 1636 ( $\mathrm{vC}=\mathrm{O}$, amide I), 1560 ( $\delta \mathrm{N}-\mathrm{H}$ amide II). Found: C 71.54, H 9.79, $\mathrm{N} 8.52 \%$. Calcd for $\mathrm{C}_{30} \mathrm{H}_{51} \mathrm{~N}_{3} \mathrm{O}_{3}$ : C 71.81, H 10.25, N 8.87\%. ${ }^{1} \mathrm{H}-\mathrm{NMR}\left(400 \mathrm{MHz}_{\mathrm{CDCl}}\right.$, TMS, $25^{\circ} \mathrm{C}$ ): $\delta=10.08(\mathrm{~s}, 1 \mathrm{H}$; NHCO), 8.12 (s, 2H; 2-benzene $\underline{\mathrm{H}}$ ), 8.10 (d, 2H; CONH$), 7.85$ (s, 1H; 4-benzene $\underline{\mathrm{H}}), 3.78$ (m, 2H; CONHC$), 2.31$ (t, 2H; $\left.\mathrm{NHCOC}_{2}\right), 1.59$ (m, 2H; $\left.\mathrm{NHCOCH}_{2} \underline{\mathrm{CH}}_{2},\right), 1.50$ (m, 8H; $\left.\mathrm{CH}\left(\underline{\mathrm{C}}_{2} \mathrm{CH}_{3}\right)_{2}\right), 1.26$ (m, 16H; $\left.\mathrm{C}_{8} \underline{\mathrm{H}}_{16} \mathrm{CH}_{3}\right), 0.86$ (t, $15 \mathrm{H}$; $\left.\mathrm{CH}_{2} \underline{\mathrm{CH}}_{3}\right)$.

PEG-containing gelator (G8): A mixture of 3.30 g (ca. 0.33 mmol) of poly(ethylene glycol) (average $\mathrm{Mn}=10,000), 0.37 \mathrm{~g}$ $(0.67 \mathrm{mmol})$ of $\mathrm{N}$-(6-isocyanatohexylaminocarbonyl)-Lisoleucylaminooctadecane, ${ }^{67}$ and $4 \mathrm{mg}(6.7 \mu \mathrm{mol})$ of dibutyl tin(IV) dilaurate in $30 \mathrm{~mL}$ of chloroform was refluxed for $24 \mathrm{~h}$ under an argon atmosphere. The filtrate from the resulting hot mixture was concentrated and poured into $100 \mathrm{~mL}$ of methanol. The precipitate was suction filtered and dried. Yield: $3.3 \mathrm{~g}(89 \%)$. FT-IR $\left(\mathrm{KBr}, \mathrm{cm}^{-1}\right): 3375(\mathrm{vN}-\mathrm{H}, \mathrm{urea}), 3275(\mathrm{vN}-\mathrm{H}$, amide), $1685(v \mathrm{C}=\mathrm{O}$, urethane), $1679(\mathrm{v} \mathrm{C}=\mathrm{O}$, amide $\mathrm{I}), 1560(\delta \mathrm{C}=\mathrm{O}$, amide II).

Polydimethylsiloxane-containing gelator (G9): A mixture of $3.30 \mathrm{~g}$ (ca. $0.66 \mathrm{mmol}$ ) of carbinol terminated polydimethylsiloxane $(\mathrm{Mw}=4500-5500), 0.74 \mathrm{~g}(1.34 \mathrm{mmol})$ of $\quad \mathrm{N}$-(6-isocyanatohexylaminocarbonyl)-L-isoleucylaminooctadecane, and $8.5 \mathrm{mg}(13.4 \mu \mathrm{mol})$ of dibutyltin(IV) dilaurate in $50 \mathrm{~mL}$ of chloroform was refluxed $24 \mathrm{~h}$ under an argon atmosphere. The resulting hot mixture was filtered and the filtrate was concentrated and poured into $100 \mathrm{~mL}$ of methanol. The formed gel was broken and suction filtered. Yield: $2.91 \mathrm{~g}$ (72\%). FT-IR $\left(\mathrm{KBr}, \mathrm{cm}^{-1}\right)$ : $3335(v \mathrm{~N}-\mathrm{H}$, urea), $3298(v \mathrm{~N}-\mathrm{H}$, amide), $1682(\mathrm{vC}=\mathrm{O}$, urethane), $1627 \mathrm{v}(\mathrm{C}=\mathrm{O}$, amide $\mathrm{I}), 1571$ $(\delta \mathrm{C}=\mathrm{O}$, amide $\mathrm{II})$.

PC-L-isoleucylaminooctadecane (G12); Phosphorylcholine (PC)-containing gelator $\mathbf{G 1 2}$ was prepared via two reactions. A mixture of $13.0 \mathrm{~g}$ (34 mmol) of L-isoleucylaminooctadecane and $2.59 \mathrm{~g}(36 \mathrm{mmol})$ of $\beta$-propiolactone in $20 \mathrm{~mL}$ of dry THF was refluxed overnight under an argon atmosphere. After evaporating, recrystallization from a mixture of THF and hexane gave $5.66 \mathrm{~g}(62 \%)$ of $\mathrm{N}$-2-hydroxyethylcarbonyl-L-isoleucylaminooctadecane. FT-IR $\left(\mathrm{KBr}, \mathrm{cm}^{-1}\right): 3285(v \mathrm{O}-\mathrm{H}$ and $v \mathrm{~N}-\mathrm{H}$ amide), 1634 ( $(\mathrm{C}=\mathrm{O}$, amide $\mathrm{I}), 1543$ ( $\mathrm{\delta N}-\mathrm{H}$ amide $\mathrm{II})$. Found: $\mathrm{C}$ 71.35, H 12.12, N 6.42\%. Calcd for $\mathrm{C}_{27} \mathrm{H}_{50} \mathrm{~N}_{2} \mathrm{O}_{3}$ : C 71.31, $\mathrm{H}$ 11.97, N 6.16\%.

2-Chloro-1,3,2-dioxaphospholane-2-oxide $\quad(0.47$ g, 33 $\mathrm{mmol}$ ) and $0.37 \mathrm{~g}$ ( $36 \mathrm{mmol})$ of triethylamine were added to a solution of $1.50 \mathrm{~g}$ (33 mmol) of $\mathrm{N}$-2-hydroxyethylcarbonyl-Lisoleucyl-aminooctadecane in $40 \mathrm{~mL}$ of dry THF and stirred for $2 \mathrm{~h}$. After removing the triethylammonium chloride, $35 \mathrm{~g}$ of trimethylamine solution (35\% in acetonitrile) was added. The resulting solution was heated for $12 \mathrm{~h}$ at $85^{\circ} \mathrm{C}$ in a sealed glass vessel. After evaporating, recrystallization from a mixture of 5 $\mathrm{mL}$ of methanol and $20 \mathrm{~mL}$ of acetonitrile gave $1.33 \mathrm{~g}$ (65\%) of G12. FT-IR $\left(\mathrm{KBr}, \mathrm{cm}^{-1}\right): 3287(\mathrm{vN}-\mathrm{H}$ amide $), 1635(\mathrm{vC}=\mathrm{O}$, amide I), $1557(\delta \mathrm{N}-\mathrm{H}$ amide $\mathrm{II}), 1049(\mathrm{v} \mathrm{P}=\mathrm{O})$. Found: C 62.21, 
H 11.08, N 6.45\%. Calcd for $\mathrm{C}_{32} \mathrm{H}_{66} \mathrm{~N}_{3} \mathrm{O}_{6} \mathrm{P}: \mathrm{C} 62.01, \mathrm{H} 10.73$, N $6.78 \%$.

\subsection{Sample preparation for TEM}

Sample preparation is illustrated in Figure 1. A weighed sample of the gelator and siloxane were placed in a test-tube and then 1 $\mathrm{mL}$ of solvent was added and heated until the gelator dissolved. A droplet of the hot solution was placed on a MICA-coated Cugrid (400 mesh). When the siloxane was only partially miscible in the solvent, the resulting suspension was dropped on a MICAcoated Cu-grid. The solvent was evaporated spontaneously at room temperature for $2 \mathrm{~h}$, and the sample was dried under vacuum overnight. In the case of specimen 2 (see Table 1), the dried sample was negatively stained with $\mathrm{OsO}_{4}$ vapor (2 wt\% acetone solution) for $10 \mathrm{~h}$.

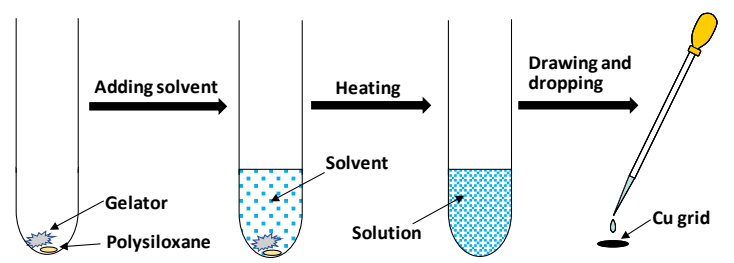

Figure 1. Illustration for staining of TEM sample using polysiloxane.

Table 1. Preparation conditions of TEM samples

\begin{tabular}{|c|c|c|c|}
\hline Specimen \# & Gelator & Siloxane & Solvent $^{1)}$ \\
\hline 1 & G1 (5 mg) & none & 1-Propanol \\
\hline 2 & G1 (5 mg) & none ${ }^{2)}$ & 1-Propanol \\
\hline 3 & G1 (5 mg) & S1 (5 mg) & 1-Propanol \\
\hline 4 & G1 (5 mg) & S1 (1 mg) & 1-Propanol \\
\hline 5 & G1 (5 mg) & S1 (10 mg) & 1-Propanol \\
\hline 6 & G1 (5 mg) & S1 (30 mg) & 1-Propanol \\
\hline 7 & G2 (10 mg) & S1 (5 mg) & Cyclohexane \\
\hline 8 & G3 (5 mg) & S1 (5 mg) & Hexane \\
\hline 9 & G4 (1 mg) & S1 (5 mg) & Toluene \\
\hline 10 & G5 (5 mg) & S1 (5 mg) & Toluene \\
\hline 11 & G6 (0.3 mg) & S1 (5 mg) & Toluene \\
\hline 12 & G7 (0.3 mg) & S1 (5 mg) & Toluene \\
\hline 13 & G8 (1 mg) & S1 (5 mg) & 1,4-Dioxane \\
\hline 14 & G9 (3 mg) & S1 (5 mg) & 1,4-Dioxane \\
\hline 15 & G10 (1 mg) & S1 (5 mg) & 1,4-Dioxane \\
\hline 16 & G11 (1 mg) & S1 (5 mg) & Dodecane \\
\hline 17 & G12 (4 mg) & S1 (5 mg) & Water \\
\hline 18 & G4 (5 mg) & none & Toluene \\
\hline 19 & G9 (3 mg) & none & 1,4-Dioxane \\
\hline 20 & G1 (5 mg) & S2 (5 mg) & 1-Propanol \\
\hline 21 & G1 (5 mg) & S3 (5 mg) & 1-Propanol \\
\hline 22 & G1 (5 mg) & S4 (5 mg) & 1-Propanol \\
\hline 23 & G1 (5 mg) & S5 (5 mg) & 1-Propanol \\
\hline 24 & G1 (5 mg) & S6 (5 mg) & 1-Propanol \\
\hline 25 & G1 (5 mg) & S7 (5 mg) & 1-Propanol \\
\hline 26 & G1 (5 mg) & S8 (5 mg) & 1-Propanol \\
\hline 27 & G1 (5 mg) & S9 (5 mg) & 1-Propanol \\
\hline 28 & G1 (5 mg) & S10 (5 mg) & 1-Propanol \\
\hline 29 & G1 (5 mg) & S11 (5 mg) & 1-Propanol \\
\hline 30 & G1 (5 mg) & S12 (5 mg) & 1-Propanol \\
\hline 31 & G1 (5 mg) & S13 (5 mg) & 1-Propanol \\
\hline 32 & G12 (4 mg) & S5 (5 mg) & Water \\
\hline 33 & G1 (5 mg) & S1 (10 mg) & 1-Propanol \\
\hline 34 & G1 (5 mg) & S9 (10 mg) & 1-Propanol \\
\hline
\end{tabular}

${ }^{1)}$ The amount of solvent was fixed to be $1 \mathrm{~mL}$.

${ }^{2)}$ The sample was negatively stained by $\mathrm{OsO}_{4}$.

3. Results and Discussion
Negative staining is one of the most commonly employed electron staining techniques for TEM. The heavy metals permeate the gaps in the sample on the supporting film to provide contrast for the TEM image. For instance, a solution containing the material under investigation is dropped onto a supporting film and then the solvent is removed from the sample. The resulting samples are stained mainly by one of two methods. One involves a staining solution containing heavy metals, such as uranium acetate or phosphotungstic acid, and the other involves deposition of heavy metals by vapor sublimation of compounds such as $\mathrm{OsO}_{4}$ and $\mathrm{RuO}_{4}$. The heavy metal materials permeate the gaps in the sample, and, as a result, these regions appear dark due to the strong scattering of incident electrons. Because the sample itself is not stained, this technique is termed negative staining. In the present study, we stained the 3D network structures of gels formed by gelators using polysiloxanes instead of heavy metals. The present staining method is sufficiently safe and easy to perform that the sample can be prepared by simply drying after a solution containing the polysiloxane is dropped onto a supporting film.

\subsection{Gelators and siloxanes}

The structures of the thirteen siloxanes (S1-S13) and twelve gelators (G1-G12) used in this study are shown in Schemes 1 and 2. G2, G4, G5, G10, and G11 were previously reported by our group, and the other gelators were prepared in this study for the first time. All the siloxanes used as stains are commercially available liquids. The TEM sample preparation conditions are summarized in Table 1, where the italic specimen number of each sample corresponds to the number inserted in the TEM images given later. The gelation test results for G1, G3, G6-G9, and $\mathbf{G 1 2}$ are summarized in Table S1.

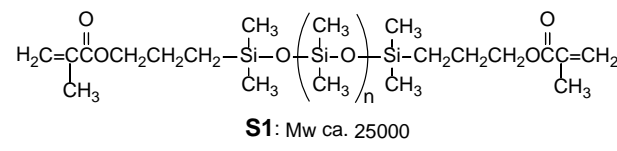

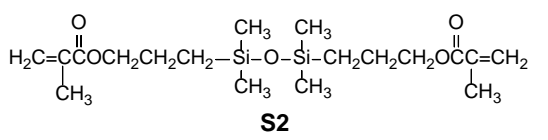

$$
\begin{aligned}
& \left.\mathrm{CH}_{3} / \mathrm{CH}_{3}\right) \mathrm{CH}_{3} \\
& \mathrm{NH}_{2} \mathrm{CH}_{2} \mathrm{CH}_{2} \mathrm{CH}_{2}-\mathrm{Si}-\mathrm{O}-\mathrm{Si}-\mathrm{O}-\mathrm{Si}-\mathrm{CH}_{2} \mathrm{CH}_{2} \mathrm{CH}_{2} \mathrm{NH}_{2} \\
& \mathrm{C}_{3} \backslash \mathrm{CH}_{3} / \mathrm{n} \mathrm{CH}_{3} \\
& \text { S3: Mw 900-1000 } \\
& \text { S4: Mw ca. } 3000
\end{aligned}
$$

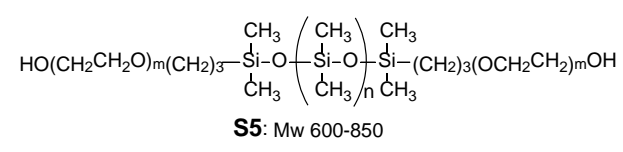

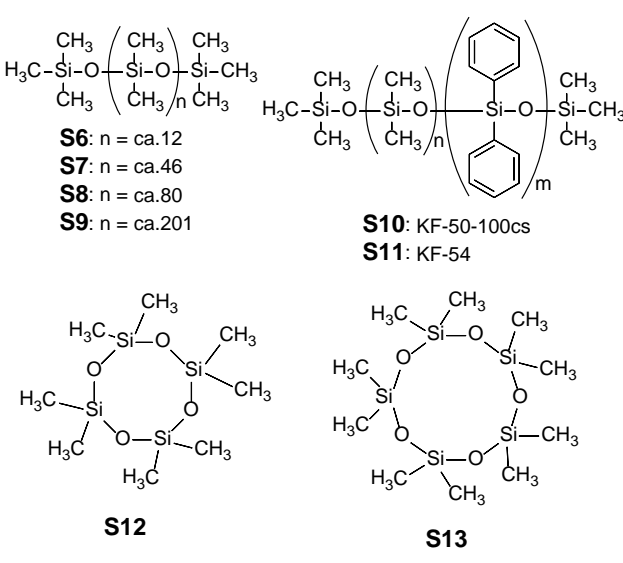

Scheme 1. Structures of siloxanes S1-S13. 

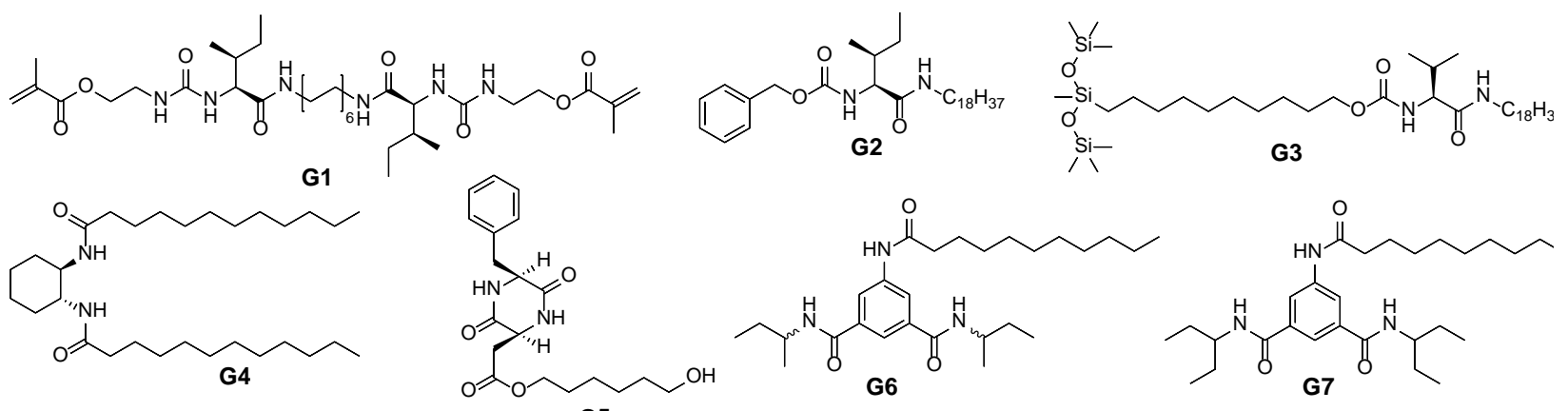

${ }_{18} \mathrm{H}_{37}+\mathrm{O}_{\mathrm{G}}^{\mathrm{N}}$

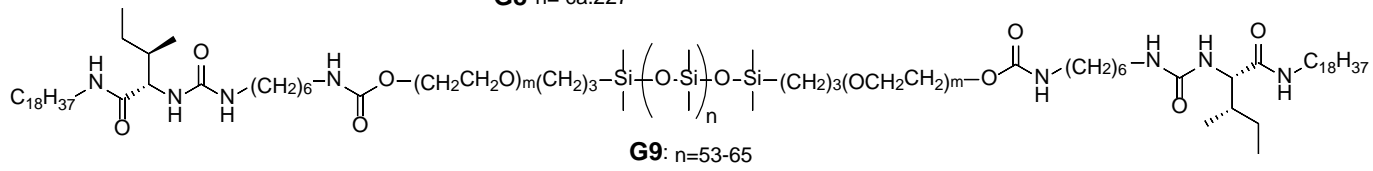

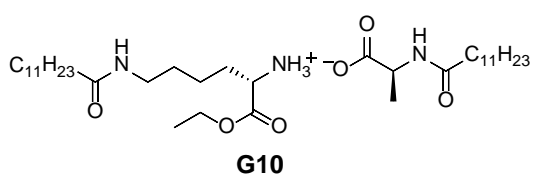

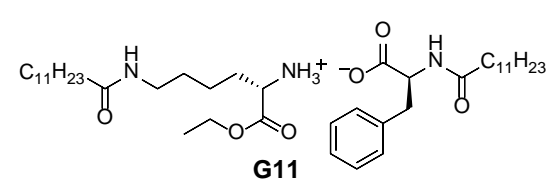

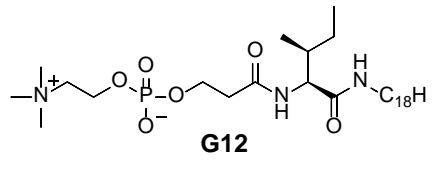

Scheme 2. Structures of gelators G1-G12.

\subsection{Comparison of non-stained, $\mathrm{OsO}_{4}$-stained, and siloxane- stained samples}

TEM images of non-stained, $\mathrm{OsO}_{4}$-stained, and S1-stained samples of molecular aggregates formed by G1 in 1-propanol, are shown in Figure 2. Since the minimum gel concentration of G1 in 1-propanol is $10 \mathrm{mg} \mathrm{mL}^{-1}$ (see Table S1), the concentration ( $5 \mathrm{mg} \mathrm{mL}^{-1}$ ) for preparing the TEM samples is half the minimum gel concentration. Therefore, it is assumed that the images in Figure 2 show fibers of loose gels before actual gelation. Specimen 1 is an image of non-stained $\mathbf{G 1}$, where low-contrast molecular aggregates with widths of 10-200 nm are observed. In general, the contrast in TEM images is brought about by the difference in the electronic dose of an electron beam transmitted through a sample. Considering that both the reflection and transmission of an electron beam depends on the electron density of a sample, the contrast in the image observed for non-stained G1 is most likely provided by the relatively high electron density of the two methacryloyloxy segments. It seems that the thick molecular aggregates in specimen 1 result from the gathering and fusing the several thin fibrous aggregates, although it is also possible that they were flattened by the heat of the electron beam. Specimen 2 is an image of $\mathrm{OsO}_{4}$-stained $\mathbf{G 1}$ obtained from a dried sample of the loose $\mathbf{G} 1$ gel stained by $\mathrm{OsO}_{4}$ vapor for $10 \mathrm{~h}$. Though the contrast in specimen 2 is somewhat better than that in specimen 1, undefined molecular aggregates with widths of 10-200 nm are still observed. Specimen 3 is an image of G1 stained by S1. A hot solution containing $5 \mathrm{mg} \mathrm{G1}$ and $5 \mathrm{mg} \mathrm{S1}$ in $1 \mathrm{~mL}$ 1-propanol was dropped onto a Cu-grid and dried overnight. The image of specimen 3 is characterized by bundles of fibers with widths of $40-200 \mathrm{~nm}$ consisting of fine fibers with widths of approximately $10 \mathrm{~nm}$. The inner and outer parts of the fibers appear white and dark, respectively, so the molecular aggregates are very clear. It can be assumed that $\mathbf{S 1}$ assembles around aggregates of $\mathbf{G 1}$ during the drying process. Consequently, the aggregates are wrapped in S1. Because Si belongs to the second period in group 14 of the periodic table, the electron density of the aggregates wrapped in S1 is higher than that in the rest of the sample. Moreover, since the bundles in specimen 3 are clearly formed by the gathering of fine fibers, it is reasonable that the wrapping of fibers by $\mathbf{S 1}$ stabilizes the individual fibers and reinforces them. Thus, the predominant staining effect of $\mathbf{S 1}$ is explained by these factors. Furthermore, $\mathrm{S1}$ is a more useful staining agent compared with $\mathrm{OsO}_{4}$, which is both expensive and strongly toxic.
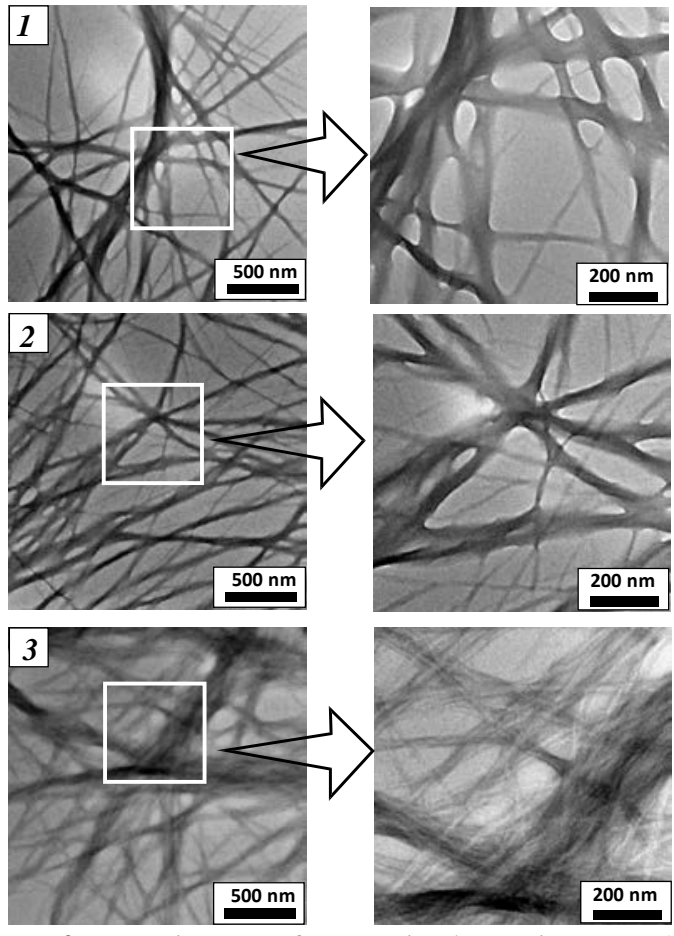

Figure 2. TEM images of non-stained (specimen 1), $\mathrm{OsO}_{4-}$ stained (specimen 2), and S1-stained (specimen 3) samples of molecular aggregates formed by $\mathbf{G 1}$ in 1-propanol. Right images are enlarged partial detail. 
Figure 3 shows images of $\mathbf{G 1}$ aggregates stained using $\mathbf{S 1}$ at various concentrations corresponding to specimens $3,4,5$, and 6 in Table 1. The staining effect for specimen 4, which was stained using $1 \mathrm{mg} \mathrm{mL}^{-1} \mathbf{S 1}$, is only partially observed. The staining effects for specimens 5 and 6 , which were stained at 10 and $30 \mathrm{mg} \mathrm{mL}^{-1}$, respectively, are highly defined, even at low magnification. Thus, it can be concluded that an S1 concentration higher than $5 \mathrm{mg} \mathrm{mL}^{-1}$ is necessary to provide satisfactory contrast. Given that the atomic numbers of Si and Os are 14 and 76, respectively, a relatively large amount of $\mathbf{S 1}$ is necessary for efficient electron scattering.

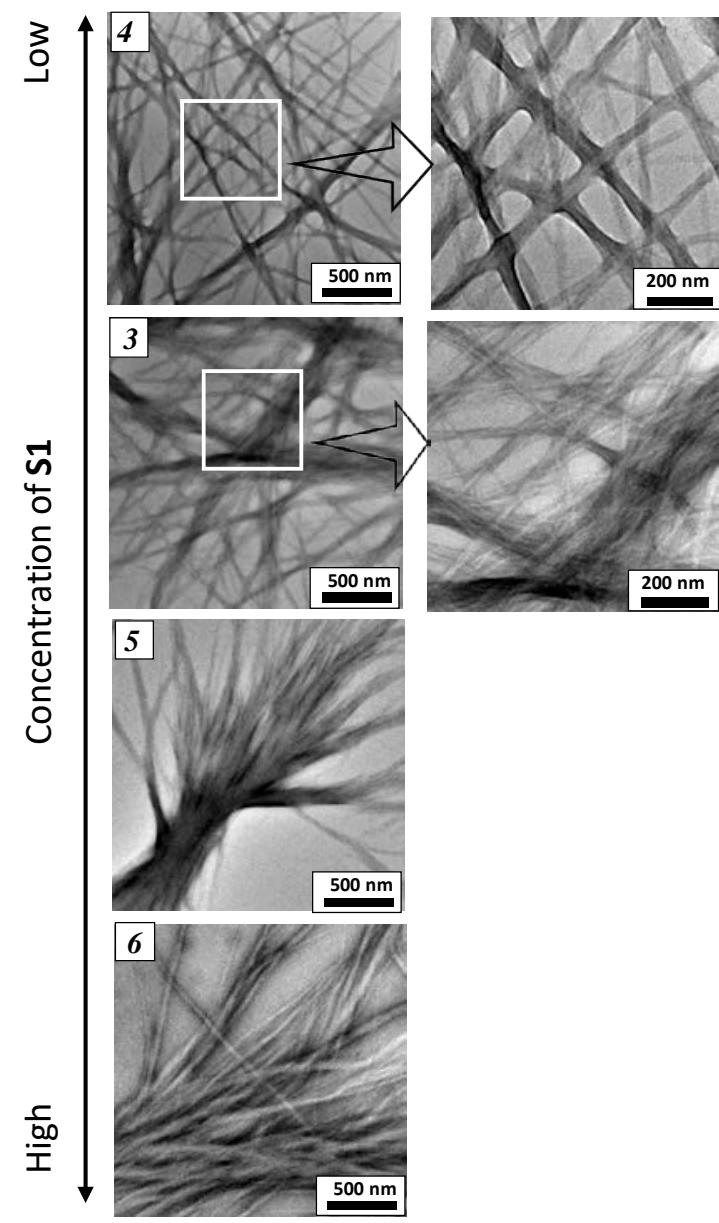

Figure 3. Images of $\mathbf{G 1}$ aggregates stained using $\mathbf{S 1}$ at various concentrations corresponding to specimens 3,4 , 5 , and 6 in Table 1.

\subsection{Staining of aggregates of different gelators by S1}

G1 may be a unique gelator in terms of the inclusion of methacryloyloxy segments. We evaluated the universality of S1 as a staining agent by using it to observe aggregates of other gelators, i.e., G2-G12. Figure 4 shows images of aggregates of G2-G12 stained by $\mathbf{S 1}$, which correspond to specimens $7-17$ in Table 1. G2-G7 are low-molecular-weight gelators and both G8 and $\mathbf{G 9}$ are polymer-based gelators. G10 and G11 are salt-type hydrogelators and $\mathbf{G 1 2}$ is a zwitterionic hydrogelator. The preparation and gelation behavior of $\mathbf{G 2},{ }^{62} \mathbf{G} 4,{ }^{61} \mathbf{G 5},{ }^{68} \mathbf{G 1 0},{ }^{69}$ and $\mathbf{G 1 1}^{69}$ are reported elsewhere. As shown in Figure 4, the images of specimens 7, 8, and 9 are of aggregates formed by G2 in cyclohexane, G3 in hexane, and G4 in toluene, where fine fibers having almost uniform diameters are observed. Although it is difficult to observe clear aggregates of $\mathbf{G 5}$ by staining with $\mathrm{OsO}_{4}$, we have succeeded in observing aggregates of $\mathbf{G 5}$ for the first time by $\mathbf{S 1}$-staining (i.e., specimen 10 ) with entangled fibers having widths of approximately $10 \mathrm{~nm}$ being clearly detected.
G6 and G7 are unique gelators that can form thixotropic gels in toluene (see Table S1). Thixotropy refers to a phenomenon whereby a gel transforms to a liquid sol by stirring or vibration, and undergoes subsequent re-gelation upon standing. The aggregates in specimen 11 are characterized by an arabesque pattern composed of fibers tangled in knots or snarls. The aggregates in specimen 12 apparently comprise fine fibers with widths of several nanometers and reach widths of approximately $100 \mathrm{~nm}$. The aggregates formed by the polymer-based gelators G8 and G9 in 1,4-dioxane are also observed as definite fibers by S1 staining (specimens 13 and 14). The ionic gelators (G10 G12) form helically knitted aggregates with widths of approximately $20 \mathrm{~nm}$ (specimens 15, 16, and 17). It is interesting to note that the aggregates formed by $\mathbf{G 1 2}$ in water can be observed by S1 staining (specimen 17). This is somewhat surprising because $\mathbf{S 1}$ is only sparingly soluble in water. Thus, the results in Figure 4 demonstrate that $\mathbf{S 1}$ can work universally as a stain regardless of the kind of gelator observed or the polarity of the solvent.
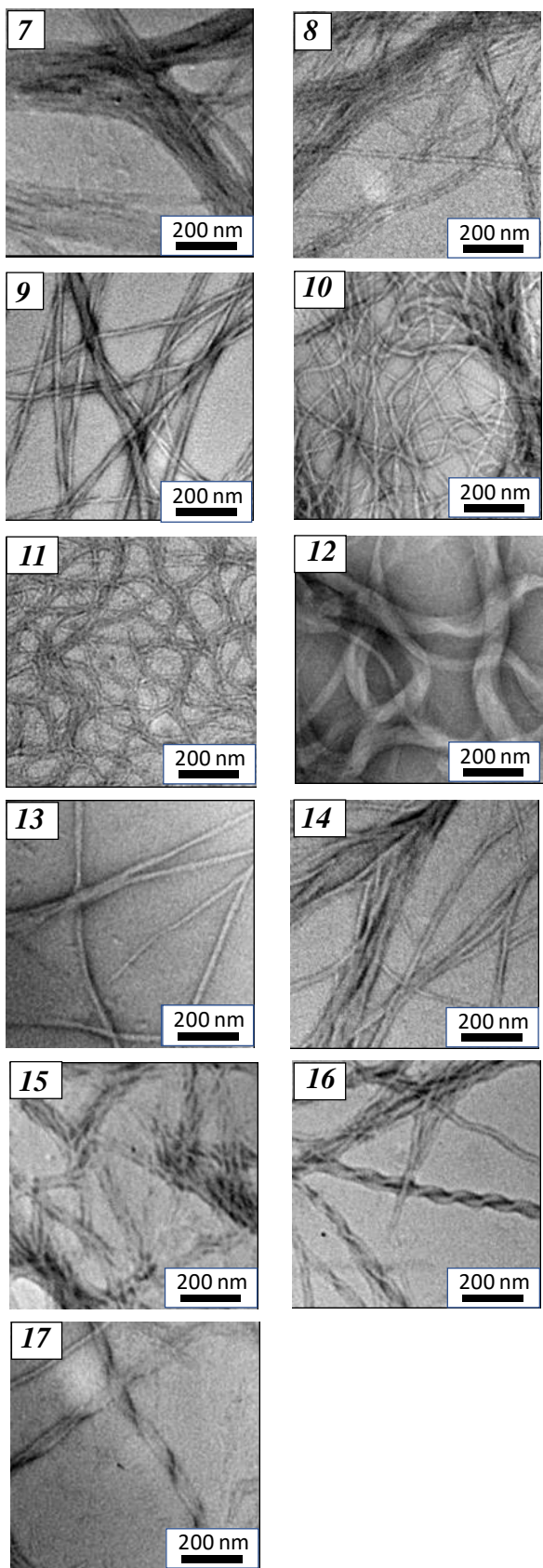

Figure 4. Images of aggregates of G2-G12 stained by S1, which correspond to specimens $7-17$ in Table 1. 


\subsection{Self-staining by siloxane-segment-containing gelators}

If $\mathrm{Si}$ atoms can scatter an electron beam efficiently, it should be possible to observe aggregates of G3 and G9 clearly without any staining because they contain siloxane segments. Figure 5 shows images of aggregates of G3 in toluene and G9 in 1,4-dioxane, which were not stained. Compared to the fine fibers with uniform diameters of approximately $20 \mathrm{~nm}$ observed in specimens 9 and 14 (Figure 4), the images of specimens 18 and 19 are thick, poorly contrasted, and indistinct. Given that indistinct thick fibers are the result of flattening by the heat of the electron beam, staining by $\mathbf{S 1}$ is very significant from the standpoint of the wrapping of fibers and the stabilization and reinforcement of individual fibers. We can conclude that selfstaining due to the siloxane segment in G3 and G9 is insufficient owing to the $\mathrm{Si}$ atoms being homogeneously dispersed throughout the aggregates. Figure 6 shows an illustration of the aggregates for non-staining and $\mathbf{S 1}$ staining. When the samples are not stained by $\mathbf{S 1}$, the aggregates are flattened and fused by the heat of the electron beam and are consequently observed as indistinct thick fibers (top of Figure 6). Conversely, if the samples are prepared in the presence of S1, the aggregates are wrapped during the drying process and both stabilized and reinforced by the $\mathbf{S 1}$ (bottom of Figure 6). There is a possibility that $\mathbf{S 1}$ has high affinity to the bundles of fibers through van der Waals interactions.
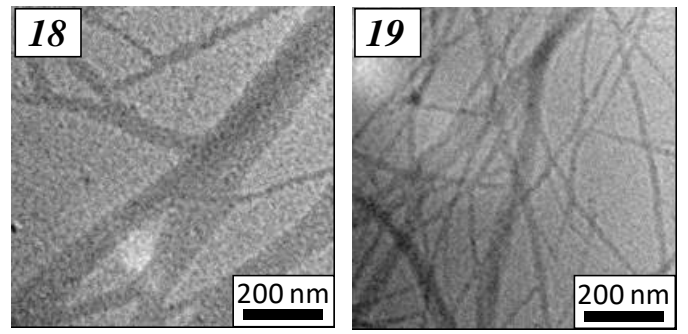

Figure 5. Images of non-stained aggregates of $\mathbf{G} 3$ in toluene (specimen 18) and G9 in 1,4-dioxane (specimen 19).
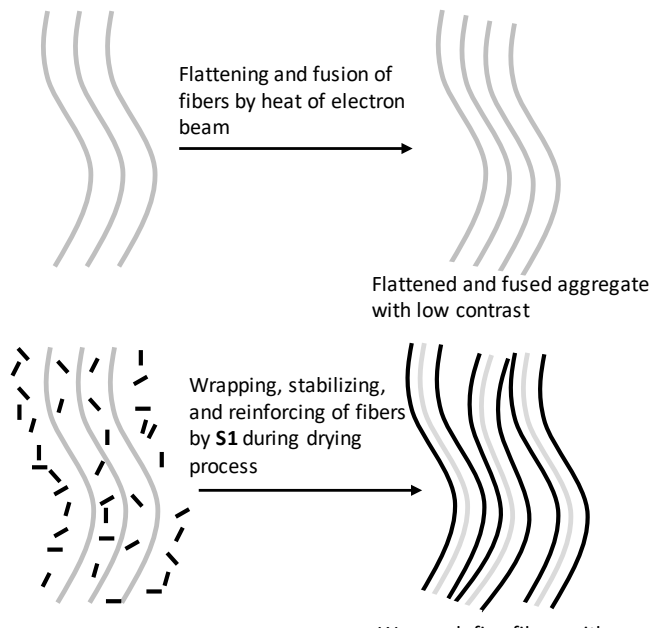

Wrapped fine fibers with high contrast

Figure 6. Process of sample preparation in the absence (above) and presence of $\mathbf{S 1}$ (below).

\subsection{Staining effect of different siloxanes}

S1 has two methacryloyloxy segments at each end. However, we reasoned that this unique structure may not necessarily be indispensable for efficient staining. To establish the importance
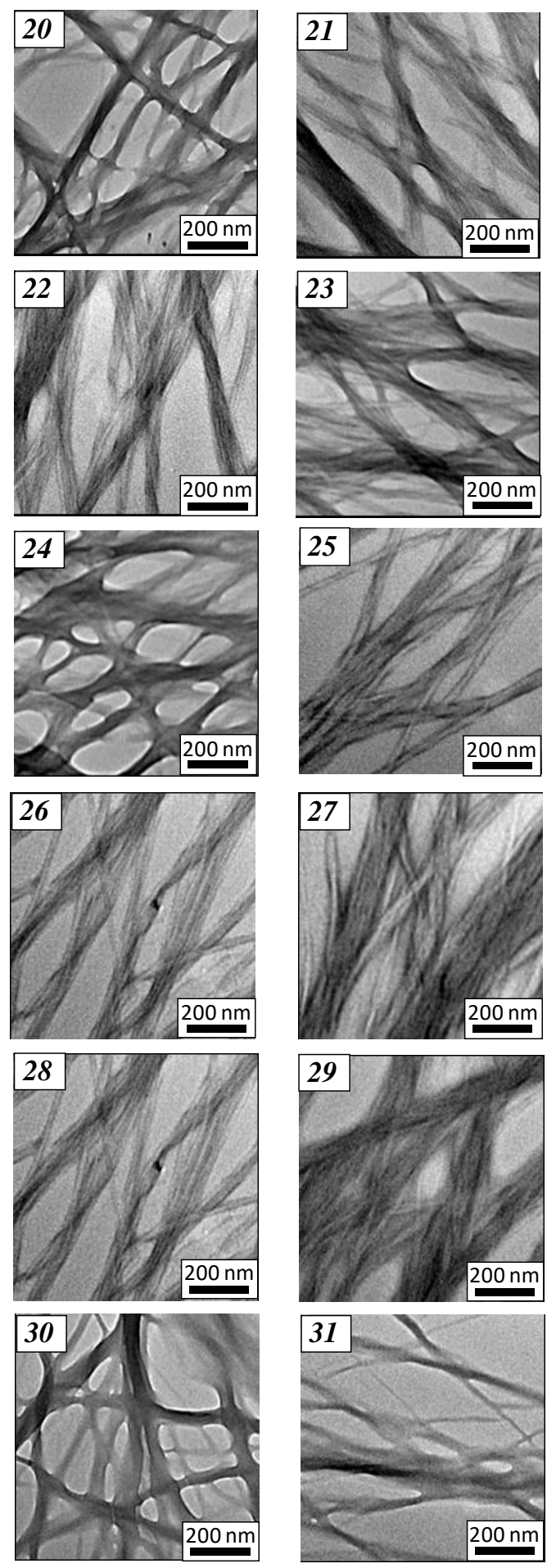

Figure 7. Images of aggregates of $\mathbf{G 1}$ stained by S2-S13, which correspond to specimens 20-31 in Table 1.

of the Si atoms, the staining effects when other siloxanes are used were investigated. Images of the aggregates of $\mathbf{G 1}$ stained by S2-S13, which correspond to specimens 20-31 in Table 1, are compared in Figure 7. First, we assessed the necessity of functional groups at both ends of the siloxanes by using S4, S5, and S8, which are aminopropyl-terminated polydimethylsiloxane, carbinol-terminated polydimethylsiloxane, and ordinary polydimethylsiloxane, respectively. The fine images observed for specimens 22, 23, and 26 indicate that the staining effect is not related to the presence or absence of the functional groups. Conversely, fine images are not observed when S2, S6, 
S12, or S13 are used as stains (see specimens 20, 24, 30, and 31). This result can be explained by the volatility of these siloxanes owing to their low molecular weight, i.e., S2 $(\mathrm{Mw}=386.64)$, $\mathbf{S 6}$ $(\mathrm{Mw}=$ ca. 1,000), S12 $(\mathrm{Mw}=296.61)$, and S13 $(\mathrm{Mw}=370.77)$. Sample preparation and observation for TEM are performed under high vacuum, meaning that S2, S6, S12, and S13 molecules after staining will be eliminated. The staining effect of S3 (Mw $=900-1,000)$ is somewhat inferior to that of S4 (Mw $=$ ca. 3000), indicating that siloxanes with molecular weights above 1,000 are necessary for efficient staining. It should be mentioned that staining by S2, S6, S12, and S13 is not observed, even though ten-times the amount was used. Thus, it is concluded from Figure 7 that the staining effect is not related to the kind of siloxane used provided it possess a molecular weight higher than 1,000.

In spite of the fact that the $\mathbf{S 1}$ is sparingly soluble in water, it is effective for staining the aggregate formed by $\mathbf{G 1 2}$ in water, and helically knitted fibers with widths of approximately $20 \mathrm{~nm}$ are observed (see specimen 17). We tried staining the aggregate formed by $\mathbf{G 1 2}$ in water by S5, i.e., the carbinol-terminated polydimethylsiloxane, which is more hydrophilic than S1. Specimen 32 in Figure 8, in which specimen 17 is also shown, is an image of the aggregate formed by $\mathbf{G 1 2}$ in water. The image of specimen 32 is very similar to that of specimen 17 in terms of the shape and size of the helically knitted fibers. The similarity of specimens 17 and 32 strongly suggests that the images observed in this study are not artifacts and that the present staining method guarantees reproducibility and universality.
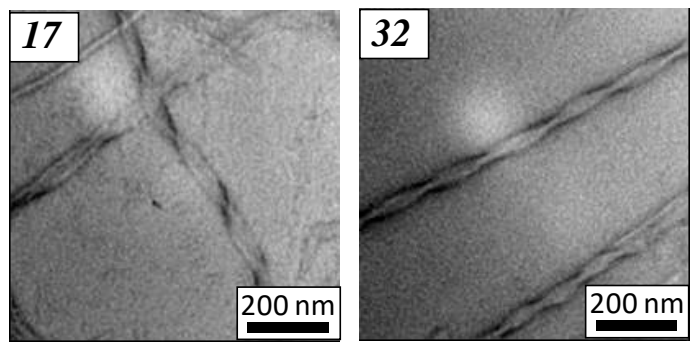

Figure 8. Images of aggregates of G12 in water, stained by $\mathbf{S 1}$ (specimen 17) and S5 (specimen 32).

\subsection{Positioning of Si atom by EDS}

EDS-equipped TEM was used to investigate the positioning of the Si atoms. Figure 9 shows an image of $\mathbf{G 1}$ stained by $\mathbf{S 1}$ (specimen 33) and two cross-sectional areas on the Cu-grid as monitored by EDS. Si atoms are detected at high concentration on the fibers and hardly at all on all the other areas. This indicates that the molecules of $\mathbf{S 1}$ gather on the surfaces of the fibers during the drying process and then wrap around the fibers. The condensation of polydimethylsiloxane around the fibers is also observed in the image of $\mathbf{G 1}$ stained by S9 in specimen 34 (Figure S1). A small amount of $\mathbf{S 9}$ is detected in areas other than the fibers.

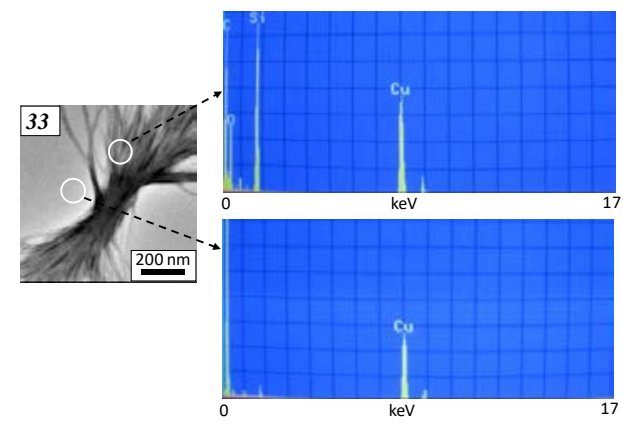

Figure 9. Image of $\mathbf{G 1}$ stained by $\mathbf{S 1}$ (specimen 33) and two cross-sectional areas on the Cu-grid as monitored by EDS.

\section{Conclusion}

The staining effect of $\mathrm{Si}$ atoms on TEM samples was investigated using aggregates of loose gels formed by twelve structurally different gelators (G1-G12) in different solvents. Thirteen commercially available siloxanes were assessed as stains. TEM images of non-stained and $\mathrm{OsO}_{4}$-stained samples of molecular aggregates formed by $\mathbf{G 1}$ in 1-propanol were undefined and poorly contrasted. The image of the S1-stained sample was characterized by very clear bundles of fine fibers, which is explained by the wrapping of fibers and the consequent stabilization and reinforcing of individual fibers by S1. S1 concentrations higher than $5 \mathrm{mg} \mathrm{mL}^{-1}$ were required to achieve satisfactory contrast. S1 was successfully applied to the observation of aggregates of not only $\mathbf{G 1}$ but also the other gelators G2-G12. The self-staining effect of the siloxane segments in $\mathbf{G 3}$ and $\mathbf{G 9}$ is insufficient due to the $\mathrm{Si}$ atoms homogeneously dispersing throughout aggregates. S1 works universally as a stain for the aggregates, regardless of the kind of gelator and the polarity of the solvent. The staining effect was observed for other siloxanes (S3, S4, S5, S7, S8, S9, S10, and $\mathbf{S 1 1}$ ) as well as $\mathbf{S 1}$. Thus, the staining efficiency depends on the molecular weight of the siloxane rather than its type, with an $\mathrm{Mw}$ of $>1,000$ being necessary. EDS indicated that molecules of S1 gather on the surface of the fibers during the drying process and wrap around them. Thus, the results obtained in this study indicate that the observed images are not artifacts and that the present staining method guarantees reproducibility and universality.

\section{Acknowledgement}

The present research was supported by JSPS KAKENHI Grant Number JP24655101.

\section{References}

1 M. A. Hayat, Principles and Techniques of Electron Microscopy, Biological Applications Vol. 1, Litton Educational Publishing, 1970.

2 M. A. Hayat, Electron Microscopy of Enzymes, Principles and Methods Vol. 1, Litton Educational Publishing, 1973.

3 M. A. Hayat, Basic Techniques for Transmission Electron Microscopy, Academic, Florida, 1986.

4 D. B. Williams, C. B. Carter, Transmission Electron Microscopy, A Textbook for Materials Science, Springer, 2009.

5 C. B. Carter, D. B. Williams, Transmission Electron Microscopy, Diffraction, Imaging, and Spectrometry, Springer, Switzerland, 2016.

6 J. M. Zuo, J. C. H. Spence, Advanced Transmission Electron Microscopy, Imaging, Diffraction in Nanoscience, Springer, New York, 2017.

7 T. Kunitake, Y. Okahata, J. Am. Chem. Soc. 1977, 99, 3860-3861.

8 T. Kunitake, Y. Okahata, J. Am. Chem. Soc. 1979, 101, 5231-5234.

9 Y. Okahata, S. Tanamachi, M. Nagai, T. Kunitake, J. Colloid Interface Sci. 1981, 82, 401-417.

10 A. Kumano, T. Kajiyama, M. Takayanagi, T. Kunitake, Y. Okahata, Bull. Chem. Soc. Jpn. 1985, 58, 1205-1209.

11 J. J. Jones, R. P. Burford, Polym. International 1991, 26, 163-170.

12 G. T. Oostergetel, F. J. Esselink, G. Hadzzioannou, Langmuir 1995, 11, 3721-3724.

13 S. Setz, F. Stricker, J. Kressler, T. Duschek, R. Mülhaupt, J. Appl. Polym. Sci. 1996, 59, 1117-1129.

14 J. S. Fodor, R. M. Briber, T. P. Russell, K. R. Carter, J. L. 
Hedrick, R. D. Miller, J. Polym. Sci. B, Polym. Phys. 1997, 35, 1067-1076.

15 D. J. Pochan, S. P. Gido, J. Zhou, J. W. Mays, M. Whitmore, J. Polym. Sci. B, Polym. Phys. 1997, 35, 2629-2643.

16 K. Oksman, H. Lindberg, A. Holmgren, J. Appl. Polym. Sci. 1998, 69, 201-209.

17 S. Hong, A. A. Bushelman, W. J. MacKnight, S. P. Gido, D. J. Lohse L. J. Fetters, Polymer 2001, 42, 5909-5914.

18 A. Adedeji, S. Lyu, C. W. Macosko, Macromolecules 2001, 34, 8663-8668.

19 A. Vazquez, M. López, E. Serrano, A. Valea, N. E. Zafeiropoulos, I. Mondragon, J. Appl. Polym. Sci. 2008, 110, 3624-3637.

20 H. L. Frisch, Y. Xue, Polym. J. 1994, 26, 828-832.

21 R. Godehardt, S. Rudolph, W. Lebek, S. Goerlitz, R. Adhikari, E. Allert, J. Giesemann, G. H. Michler, J. Macromol. Sci. Phys. 1999, B38, 817-835.

22 F. Cser, F. Rasoul, E. Kosior, Polym. Eng. Sci. 1999, 39, 1100-108.

23 M. F. Ottaviani, P. Matteini, M. Brustolon, N. J. Turro, S. Jockusch, D. A. Tomalia, J. Phys. Chem. B 1998, 102, 6029-6039.

24 M. F. Ottaviani, P. Favuzza, M. Bigazzi, N. J. Turro, S. Jockusch, D. A. Tomalia, Langmuir 2000, 16, 7368-7372.

25 S.-E. Stiriba, M. Q. Slagt, H. Kautz, R. J. M. K. Gebbink, R. Thomann, H. Frey, G. Koten, Chem. Eur. J. 2004, 10, 1267-1237.

26 M. R. Moghbeli, N. Mohammadi, R. Bagheri, S. R. Ghaffarian, Polymer 2003, 44, 4011-4019.

27 D. I. Lee, J. Polym. Sci. A, Polym. Chem. 2006, 44, 28262836.

28 N. Pukkate, T. Kitai, Y. Yamamoto, T. Kawazura, J. Sakdapipanich, S. Kawahara, Eur. Polym. J. 2007, 43, 3208-3214.

29 S.-X. Li, W.-F. Wang, L.-M. Liu, G.-Y. Liu, Polym. Bull. 2008, 61, 749-757.

30 Y. Mogi, M. Nomura, H. Kotsuji, K. Ohnishi, Y. Matsushita, I. Noda, Macromolecules 1994, 27, 67556760 .

31 W. P. Chen, M. F. Zhu, S. Song, B. Sun, Y. M. Chen, H. J. P. Adler, Macromol. Mater. Eng. 2005, 290, 669-674.

32 G. G. Ferrer, M. S. Sanchez, J. L. G. Ribelles, F. J. R. Colomer, M. M. Pradas, Euro. Polym. J. 2007, 43, 31363145.

33 D. P. Harland, J. A. Vernon R. J. Walls, J. L. Woods, J. Microsc. 2011, 243, 184-196.

34 M. Huo, M. Zeng, D. Li, L. Lei, Y. Wei, J. Yuan, Macromolecules 2017, 50, 8212-8220.

35 H. Stara, M. Slouf, F. Lednicky, E. Pavlova, J. Baldrian, Z. Stary, J. Macromol. Sci. B Phys. 2008, 47, 1148-1160.

36 S. Mann, R. J. P. Williams, J. Chem. Soc. Chem. Commun.1981, 1083-1084.

37 P. Terech, R. G. Weiss, Chem. Rev. 1997, 97, 3133-3159.

38 J. H. Esch, B. L. Feringa, Angew. Chem., Int. Ed. 2000, 39, 2263-2266.

39 L. A. Estroff, A. D. Hamilton, Chem. Rev. 2004, 104, 1201-1217.

40 P. Dastidar, Chem. Soc. Rev. 2008, 37, 2699-2715.

41 S. Banerjee, R. K. Das, U. Maitra, J. Mater. Chem. 2009, 19, 6649-6687.

42 P. Terech, R. G. Weiss, Molecular gels, materials with selfassembled fibrillar networks, Springer, Dordrecht, 2006.

43 F. Fages, Low molecular mass gelators: design, selfassembly, function, Springer, Berlin, 2005.

44 M. Suzuki, K. Hanabusa, Chem. Soc. Rev. 2009, 38, 967.

45 M. Suzuki, K. Hanabusa, Chem. Soc. Rev. 2010, 39, 455.
46 J.-L. Li, X.-Y. Liu, Adv. Funct. Mater. 2010, 20, 31963216.

47 G. John, B. V. Shankar, S. R. Jadhav, P. K. Vemula, Langmuir 2010, 26, 17843-17851.

48 H. Svobodová, V. Noponen, E. Kolehmainen, E. Sievänen, RSC Adv. 2012, 2, 4985-5007.

49 S. S. Babu, S. Prasanthkumar, A. Ajayaghosh, Angew. Chem., Int. Ed. 2012, 51, 1766-1776.

50 A. Y.-Y. Tam, V. W.-W. Yam, Chem. Soc. Rev. 2013, 42, 1540-1567.

51 J. Raeburn, A. Z. Cardoso, D. J. Adams, Chem. Soc. Rev. 2013, 42, 5143-5156.

52 G. Yu, X. Yan, C. Han, F. Huang, Chem. Soc. Rev. 2013, 42, 6697-6722.

53 M. D, Segarra-Maset, V. J. Nebot, J. F. Miravet, B. Escuder, Chem. Soc. Rev. 2013, 42, 7086-7098.

54 S. S. Babu, V. K. Praveen, A. Ajayaghosh, Chem. Rev. 2014, 114, 1973-2129.

55 D. K. Kumar, J. W. Steed, Chem. Soc. Rev. 2014, 43, 2080 2088.

56 V. K. Praveen, C. Ranjith, N. Armaroli, Angew. Chem., Int. Ed. 2014, 53, 365-368.

57 Y. Lan, M. G. Corradini, R. G. Weiss, S. R. Raghavanc, M. A. Rogers, Chem. Soc. Rev. 2015, 44, 6035-6058.

58 T. Tachibana, H. Kambara, Bull. Chem. Soc. Jpn. 1969, 42, 3422-3424.

59 P. Terech, R. H. Wade, J. Colloid Interface Sci. 1987, 125, 542-551.

60 K. Hanabusa, T. Miki, Y. Taguchi, T. Koyama, H. Shirai, $J$. Chem. Soc. Chem. Commun. 1993, 1382-1384.

61 K. Hanabusa, M. Yamada, M. Kimura, H. Shirai, Angew. Chem., Int. Ed. 1996, 35, 1949-1951.

62 K. Hanabusa, K. Hiratsuka, M. Kimura, H. Shirai, Chem. Mater. 1999, 11, 649-655.

63 Y. Yang, M. Suzuki, S. Owa, H. Shirai, K. Hanabusa, J. Am. Chem. Soc. 2007, 129, 581-597.

64 K. Hanabusa, T. Ueda, S. Takata, M. Suzuki, Chem. Euro, J. 2016, 22, 16937-16949.

65 H. Nakagawa, M. Fujiki, T. Sato, M. Suzuki, K. Hanabusa, Bull. Chem. Soc. Jpn. 2017, 90, 312-321.

66 Y. Imasaka, M. Sano, H. Shirai, K. Hanabusa, Polym. J. in press.

67 M. Suzuki, R. Yanagida, C. Setoguchi, H. Shirai, K. Hanabusa, J. Polym. Sci., Part A: Polym. Chem. 2008, 46, 353-361.

68 H. Hoshizawa, Y. Minemura, K. Yoshikawa, M. Suzuki, K. Hanabusa, Langmuir 2013, 29, 14666-14673.

69 M. Suzuki, H. Saito, K. Hanabusa, Langmuir 2009, 25, 8579-8585. 